\section{ASPHER Office Matters}

As the first Executive Director of ASPHER, I took my post the first of July 1995 and started by organising the office in Paris, within the premises of the satellite unit of the French National SPH in "Hôpital National de St Maurice".

This went from ordering chair, desk and PC to opening an ASPHER bank account, having the association registered in France, etc.

The so badly needed connection to EMail was supposed to be operational before the end of 1995 and it may very well be that it is finally working by the time you are reading these lines ...!

More into the content now, after close to nine months in charge, I fully realised what we all know intellectually i.e. that the strength of such an association is in its members' own strength and in their commitment to and regular contacts with their association.

The Executive Director in particular can only build on that basis to further develop the association and in return assist every member in its own development. It means for instance to keep me informed about what you are doing, what you happen to know which could be of interest for the association, etc.

The prospects for development will be fully discussed during the General Assembly in Utrecht where, among other things, a corporate plan will be examined.

On another hand, as soon as the organisation of the office in Paris will be in a more functional state, I will put at your disposal a compiled and updated information about Public Health in Europe, in relation to the Schools of Public Health interests.

\section{Task Forces and Committees}

ASPHER has established a few Task Forces (for short-term projects) and Committees (for long-term developments). They have been initially staffed mostly with Executive Board members but in the near future more and more in- stitutional members will be invited to propose to delegate a representant.

\section{Committee on PEER}

The first established was the Committee on Public health Education European Review which is composed by ASPHER members but also by delegates from EUPHA and the PH student association, and an observer from EPHA. President: L. Köhler, Sweden; Members: E. de Leeuw, The Netherlands, L. Gunning Schepers, EUPHA; Member ex officio: J.A. Bury; Observer: M. Joffe, EPHA

\section{Committee on professionalisation}

The Board agreed that ASPHER should either take the lead of the project or being an associate partner. The precise definition of professionalisation is still debated and this goes to involve or not quality insurance mechanism and definition of standards. Anyway, the involvement of ASPHER is fully justified by the strong links that it has with the training processes conducive to professions.

It has been decided that the committee within ASPHER will prepare a project proposal to be submitted to the next Board meeting. That will include the exploration of the best leader in the field which can be the ENSP in Rennes as well as the contact with EUPHA and EHMA.

President: S. Gottot, France; Members: F. Bojan, Hungary, F. Cavallo, Italy, U. Laaser, Germany; Member ex officio: J.A. Bury

\section{Committee of the ASPHER Bulletin}

The managerial responsibility for the newsletter was assigned to Evelyne de Leeuw, under the supervision of an editorial board composed of the president (Franco Cavallo), the deputy president for 1996, Ulrich Laaser (past president) and the executive director.

Jacques A. Bury

Executive Director 